\title{
La Carta internacional de los museos memoriales de IC-MEMO: una guía ética para la musealización de patrimonios disonantes
}

\author{
Eduarda Vieira | Escola das Artes, Universidade Católica Portuguesa \\ Ana Galán-Pérez | Centro de Investigação em Ciência e Tecnologia das Artes, Universidad Católica Portuguesa \\ URL de la contribución <www.iaph.es/revistaph/index.php/revistaph/article/view/5053>
}

El patrimonio cultural procedente de hechos históricos trágicos requiere profesionales de todas las áreas de gestión que comprendan sus retos y dificultades y que consigan además un equilibrio entre significancia, conservación y accesibilidad social. Una de las herramientas museológicas puestas en funcionamiento desde 2011 es la International Memorial Museums Charter de la red de ICOM IC-MEMO, una carta internacional de principios de los museos conmemorativos cuyas recomendaciones sirven de guía ética para la gestión de patrimonios disonantes. Dichos museos generalmente se emplazan en los lugares históricos donde ocurrieron los hechos trágicos, convirtiéndose dichos espacios en elemento patrimonial en si mismo, y en los que los museos se apoyan para conducir su tarea educativa y cívica a la sociedad. Así, espacio, legado intangible y el legado tangible se salvaguardan para defender la memoria de las víctimas y procurar que el mensaje de paz sea un valor inherente a la visita.

El Comité Internacional de Museos en memoria de las víctimas de crímenes públicos IC-MEMO, se fundó en el año 2001 en el marco de ICOM, Consejo Internacional de Museos, con el objetivo de conmemorar y preservar el legado que da testimonio de crímenes de Estado por razones sociales y políticas contra la humanidad. Su Carta internacional de los museos memoriales supone una serie de recomendaciones a modo de código ético que, a lo largo de diez artículos, trata la relación entre los patrimonios disonantes y su conexión con la sociedad y la memoria, esto es, la cultura de la remembranza. Aborda también la misión de los museos memoriales en el contexto social y político, y el museo memorial como institución organizada, basada en la investigación cientí- fica y humanista alejada de decisiones meramente políticas y subjetivas.

En la cultura de la remembranza, atendiendo a la Carta, participan todas las comunidades mediante la recopilación de sus memorias. A través del deseado diálogo y consenso se acuerda la fórmula para construir la memoria social como suma de las experiencias individuales. $Y$ en este proceso se encuentran las memorias de las víctimas y de los perpetradores, así como la de la sociedad contemporánea que vive este proceso de manera activa. Por tanto, es importante evitar la uniformización de la memoria colectiva ya que se están reconociendo diversos puntos de partida (Velázquez 2011, 30). Esta diversidad de las memorias se preserva en el museo memorial, partiendo de lo individual a lo colectivo, una cultura de la remembranza que es acordada entre todos los sectores de la sociedad.

No hay duda que uno de los principales retos de los museos memoriales es la relación con las víctimas, sus descendientes y las comunidades en las que se integran. No solo por tener como misión recordar y musealizar los crímenes públicos contra las minorías en la historia, sino porque dichos colectivos deben ser protegidos, así como su conservar su legado, para asegurar su independencia y alejarlos de cualquier interés político. Resulta, por tanto, relevante la respuesta de las comunidades a las que va dirigido el museo, pues son las propietarias morales de los objetos y colecciones que se exponen y custodian. Incluso, en algunos casos, el interés por la creación de estos museos parte de las propias comunidades como un acto casi de sanamiento democrático y fortalecimiento de la ciudadanía. 


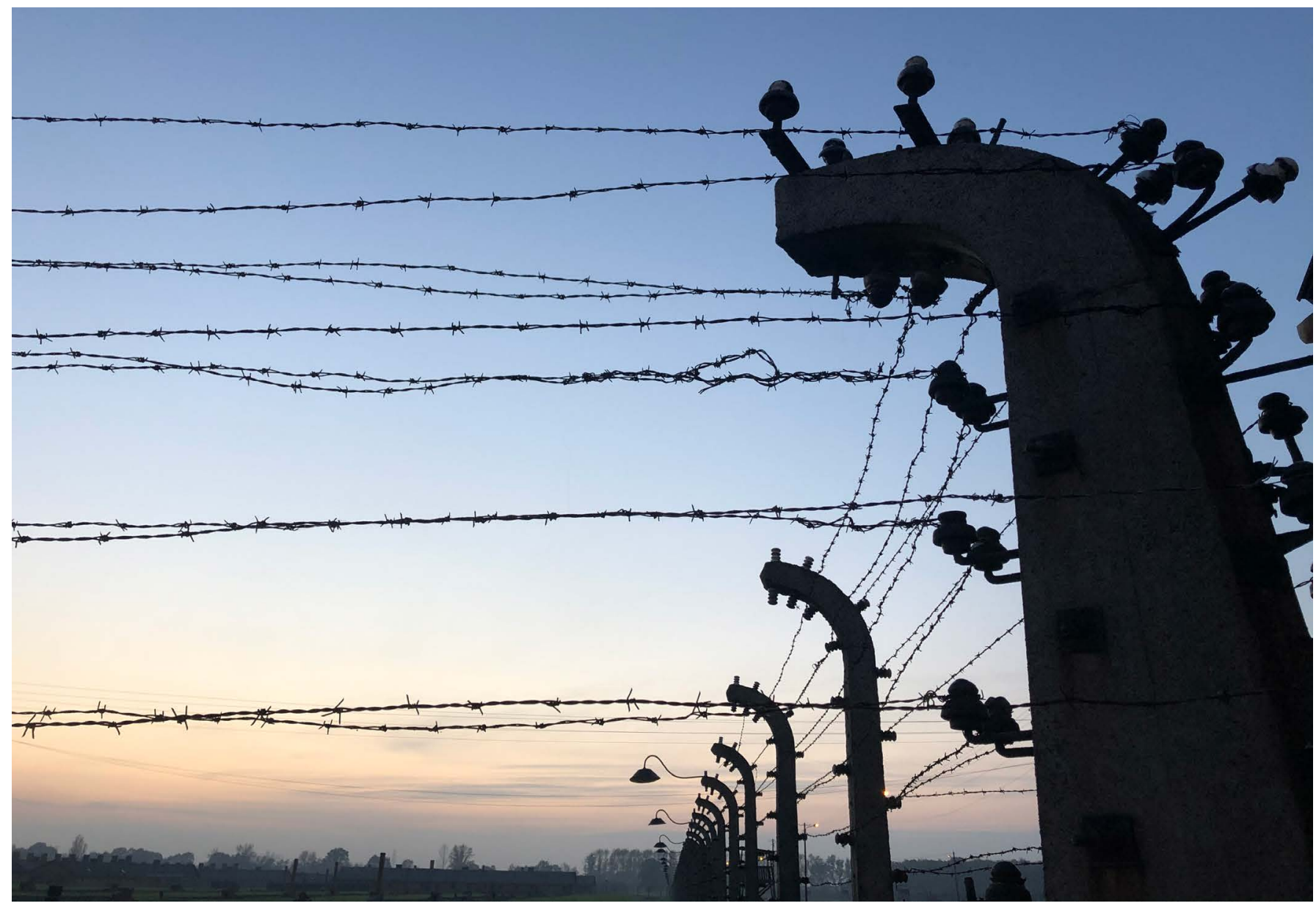

Alambrada de Auschwitz-Birkenau | Ana Galán-Pérez

Por otra parte, los museos memoriales tienen la responsabilidad de evocar empatía con aquellas personas que fueron señaladas para su persecución, por pensamiento político, por religión, por cultura, por etnia, o por no cumplir con las normas sociales determinados por el régimen totalitario en el poder. Para ello, acciones como la creación del discurso museológico con la selección de piezas de las colecciones del museo, la creación del diseño museográfico, la edición de publicaciones, y el desarrollo de las actividades educativas, han de tener presente estas premisas: empatía y cultura de la paz. Esta búsqueda de la cultura de la paz y la remembranza viene reforzada por los numerosos estudios sobre nuevos enfoques históricos y el peso de las memorias de los excluidos y silenciados, víctimas de guerras, que pasan a primera línea narrativa en su consideración y reconocimiento colectivo (Arrieta 2016, 11).

En este camino, los museos buscan la fórmula para comunicar su mensaje a toda la sociedad, analizando la participación de todas las generaciones tanto para las que vivieron los acontecimientos históricos como para las generaciones contemporáneas. El contexto de aprendizaje debe ser aquel en el que la emoción y la información de lo que se perciba a través de las colecciones musealizadas pasen a convertirse en recuerdos propios, es decir, en una cultura de la remembranza positiva y generadora de progreso social. 
En conclusión, los museos memoriales tienen como misión la salvaguarda de la memoria para que la sociedad no se olvide. Promueven la búsqueda y la defensa de los derechos humanos a través del consenso y la cooperación social y política partiendo del reconocimiento de hechos trágicos, pero también buscando y potenciando valores positivos que nos unan como comunidad, como es la paz social.

Y, finalmente, si reflexionamos sobre el sentido de valorizar los museos memoriales veremos que el camino dista de etiquetar o clasificar como objeto de consumo turístico. La realidad va mas allá: cambiemos usuarios por comunidades, públicos por ciudadanos.

\section{BIBLIOGRAFÍA}

- Arrieta I. (ed) (2016) Lugares de memoria traumática. Representaciones museográficas de conflictos políticos y armados. Bilbao: UPV

- Hernández, F.X. (2011) Conflictos contemporáneos, estrategias de musealización crítica. Revista Museo y Territorio, n. ${ }^{\circ}$ 4. Málaga: Área de Cultura del Ayuntamiento, pp. 79-86

- Galán-Pérez, A. y Vieira, E (2020) Museos memoriales, museos diferentes: buscando claves para su conservación. Diferents. Revista De Museus, n. ${ }^{\circ}$ 5, pp. 36-55. Disponible en: https://doi.org/10.6035/Diferents.2020.5.3 [Consulta: 17/11/2021]

- IC-MEMO [International Committee of Memorial Museums in Remembrance of the Victims of Public Crimes] (2011) Internacional Memorial Museum Charter. Disponible en: http://icmemo.mini.icom.museum/wp-content/uploads/ sites/17/2019/01/IC_MEMO_charter.pdf [Consulta: 17/11/2021]

- Maceira Ochoa, L. (2012) Museo, memoria y derechos humanos: itinerarios para su visita. Bilbao: Universidad de Deusto. Disponible en: http://www.deusto-publicaciones.es/ deusto/pdfs/cuadernosdcho/cuadernosdcho68.pdf [Consulta: $17 / 11 / 2021]$

- Navarro, O. (2011) Ética, museos e inclusión: un enfoque crítico. Revista Museo y Territorio, n. ${ }^{\circ} 4$. Área de Cultura del Ayuntamiento de Málaga, pp. 49-59

- Ortiz, C. y Sánzhez-Carretero, C. (2008) Archivos etnográficos, memoria y nuevos patrimonios: el caso del archivo del duelo. En: Pereiro, X., Prado, S. y Takenaka, H. (coord.) Patrimonios culturales: Educación e interpretación. Cruzando límites y produciendo alternativas. País Vasco: Ankulegi pp. $155-170$
- Velázquez, C. (2011) El museo memorial: un nuevo espécimen entre los museos de historia. Intervención (México $D F$ ), México, vol. 2, n. ${ }^{\circ} 3$, pp. 26-31. Disponible en: http://www. scielo.org.mx/scielo.php?script=sci_arttext\&pid=S2007-249X20 11000100005\&lng=es\&nrm=iso\&tlng=es [Consulta: 17/11/2021]

- Witker Barra, R. (2016) Museos de la vergüenza. El uso de la memoria política como patrimonio cultural. Illapa Mana Tukukuq, n. ${ }^{\circ}$ 13, pp. 88-97. Disponible en: https://doi. org/10.31381/illapa.v0i13.1901 [Consulta: 17/11/2021] 